\title{
An Integrated Approach to the Teaching and Learning of Cultural and Creative Arts (CCA): The Music Aspect
}

\author{
Ojukwu, Ebele V. (Ph.D.) \\ Esimone, Chinyere C. (Ph.D.) \\ Department of Music Nnamdi Azikiwe University, Awka \\ Email: drebeleojukwu@yahoo.com, adimireesomchi@yahoo.com \\ Phone: +234(0)8037244058, +234(0)8063853736
}

\section{Doi:10.5901/jesr.2014.v4n1p333}

\section{Abstract}

The need for regular reviewing and restructuring of the curriculum to ensure relevance to dynamic human society and culture and to respond to global reforms, spurred the Nigerian Educational Research and Development Council (NERDC) to review and restructure the cultural and creative arts curriculum for Basic Education in Nigeria. The curriculum provided the total experiences to which all learners must be exposed, the contents, performance objectives, activities for teachers and learners and evaluation guide. Cultural and creative arts (CCA), being an integrated subject, its teachers need to be acquainted on how best to handle each aspect in order to enhance the students' learning. This paper sets out to ensure that the curriculum is properly implemented in the area of music. It discusses the nature, philosophy and reason for teaching music as an aspect of cultural and creative arts. The objective and structure of the music aspect of CCA curriculum is also discussed. It also highlights the methods and resources for teaching music and the problems militating against effective teaching of CCA as an integrated subject. Historical method and other related resource materials were employed as working tools. The paper recommends that for the time being the different subject areas of CCA should be left and be taught as separate subjects until departments of CCA is created in the Nigerian colleges of education and other institutions where teachers are trained and produced for the basic classes.

\section{Introduction}

As society changes, so is the curriculum also changing to meet or adapt to the needs of the society. The needs of the society should be fully reflected in the educational system for relevance to be achieved. The Nigerian Educational Research and Development Council (NERDC) has developed and published new curriculum as approved by the National Council on Education (NCE) with effect from September 2007. The curriculum comprises the new 9-year Universal Basic Education Curriculum and also the New Senior Secondary Education. The new curriculum was designed to fill the gaps in the old curriculum, introduce new subjects to replace obsolete subjects, redefine core subjects and also meet the key targets of the National Economic Empowerment and Development Strategy (NEEDS). These key targets are expressed as: value re-orientation; poverty eradication; job creation; wealth generation and using education to empower the citizenry (NERDC, 2007). The implication is that the school principals and the teachers are the key people, and they are the players that will ensure that the new curriculum succeeds in schools across Nigeria.

Teachers play a vital role in the effective implementation of the changing curriculum because they are involved in very many ways in the things that learners do in school. The teacher is the principal actor in all teaching and learning situation and as a result, much centres on him/her. A good teacher must cultivate and possess some personal qualities or characteristics that will endear him/her to the learner. According to Ikeme \& Offorma in Nwokenna (2006:48) 'a teacher needs to be competent both in the content and subject pedagogy to make his teaching interesting to the learner'. Effective learning is the product of effective teaching. For both teaching and learning to be effective, much depends on the ability of the teacher who will handle the teaching and learning process and the variables that enhance teacher effectiveness. Students must be properly guided by the teachers through planned activities so that learning may be acquired. High quality education is essential if individuals are to realise their full potentials and the teacher is fundamental in that process.

'Government is transforming the education sector' to make teachers more relevant in their teaching job because quality education for young students is critical not only for individual growth, but also for a society's future (http://www.lagostelevision.com/.../minister-states-accessed-n50b-ubec-cash-in-2011-the-nation-newspaper/-31k). For 
teachers to be successful in handling the new curriculum there is need for them to study effectively their subject areas and merge it with the components of the scheme of work derived from the new curriculum which has been prepared in a thematic pattern. The nature of the topics and content areas to be taught by teachers of various subjects will determine the type of skills to be developed in the students. Cultural and creative arts as a subject therefore, is a synthesis of drama, dance, music and fine arts began with the realization that the new discipline will in theory and practice, extend beyond the constituents of each of the component parts (FME, 1988).

The cultural and creative arts (CCA) education has been listed as one of the 'core basic subjects' by NERDC in the new 9-year basic education curriculum (FGN, 2007:7). It is aimed at developing the students' acquisition of cultural repertoire, aesthetic perception, artistic talents, creativity and expression. It is designed to stimulate interest and inquires into the theoretical and practical areas, particularly as they affect the teaching of the arts in school (http://www.ncceonline.org/.../Arts.../). Cultural and creative arts education is the umbrella term which brings together the three arts subject areas; music, fine and applied arts and drama/theatre. Though, these three subject areas 'have their own distinct characteristics which largely inform their particular and varied ways of working but within that work model arguably the creative aspect is fundamental' (http://www.reading.ac uk/a-z). Creativity which is inherent in man has relevance in all the facts of life and it concerns everyone. Drama, music and fine arts constitute aesthetics that portray them as universal language and vital persistent aspects of human experience. They are essential elements of culture that gives vibrancy and dept of meaning to life and their essence manifest through creative thinking and action (Okonkwo, 2009).

\section{The Nature, Philosophy and Reason for Teaching Music as an Aspect of CCA}

Music education is a powerful instrument for manpower development because of its intellectual, social, physical, emotional and spiritual values which benefit man. Music education contributes to man's all-round development as a useful member of the family, community or nation in which he belongs. It incorporates the development of the affective domain, music appreciation and sensitivity and seeks to develop the whole person. Music education is a human behaviour that is acquired directly and learnt the same natural way a child learns language. To this extent Okafor (2005:19) wrote 'Music and education are both cultural expressions'. He further noted that music stands to be one of the principal aspects of human cultures. Nigerian government equally recognized that music education is the expression of the people which reflects the society, the environment and aspect of their culture and 'these therefore constitute the underlying principles for formulating the philosophy of cultural and creative arts education for primary/junior secondary school in Nigeria' (en.wikipedia.org/wiki/Arts_integration-cashed). The philosophy of music seeks to clarify the objective of music education and the methods used by musicians and music educators. The success of music programme in our schools depend on how much emphasis that is laid on its teaching and learning in order to achieve a well rationalized system of music education that can sustain the transmission of age-old indigenous musical knowledge, the systemized practices and creative advancement effectively. There is need for the modern music educators to be mentally and practically equipped. This will enable them inculcate in the students their cultural identity in the national and world music discourse and creative practice.

Among the reasons that can be provided to explain why music is included as an aspect of CCA curriculum are the following.

Music education in schools and colleges is a cultural mechanism designed to educate people about music and as such should reflect the place of music in the society.

- Music education is necessary to life because it educates in a broader sense and empowers the individual to explore the wider world beyond self.

- Music education serves as a vital element of the cultural process helping us and our cultures to become renewed and transformed.

- Music education serves the purpose of the preservation of the musical heritage of the people and the transformation of that heritage.

- Music is an aesthetic art of combining sound that is pleasant to the ear.

- Music is a diverse human practice of constructing aural temporal patterns for primary values of enjoyment, self growth and self knowledge.

- Music is the living analogy of human knowing, feeling, sensibility, emotions, intellectual, modus operandi and all other life giving forces which affect human behaviour and knowing. 


\section{The Objectives and Structure of the CCA Curriculum (Music Aspect)}

The CCA as an integrated field of study is goal oriented. The general objective of CCA education is to enable students' observe and explore the environment using their senses and manipulative skills to apply it to real life situations. Ekwueme (1991) outlined the aims as follows:

- To preserve, promote, project perpetuate and transmit our cultural heritage;

- Provide the opportunity for the inculcation of permanent literacy in aesthetic (musical, performing, creative and visual arts);

- Provide the opportunities for pupils to see the usefulness and relationship among subjects that make up CCA;

- Increase awareness interest and sensitivity towards our culture and towards other cultures;

- Provide a basis for moral and character training and the development of sound attitudes;

- To develop the basic skills in various art forms; and

- Promote cultural education by providing information in developing a sense of cultural and social responsibility and encouraging social participation in schools and the community (Ekwueme, 1991:220).

The expected educational goals which CCA education ought to contribute in inculcating in the students according to the Federal Government of Nigeria in its National Policy on Education (FGN: 2004) include:

Development of the individual into a sound and effective citizen; full integration of the individual into the community; inculcation of national consciousness, national unity, right type of values and attitudes for the survival of individual and Nigerian society; and acquisition of appropriate skills, development of mental, physical and social abilities and competencies as equipment for the individual to live and contribute to the development of the society (p. 7).

To enable one implement the curriculum in a logical manner, information is gathered in the unit of what one is required to teach, why one has to teach that aspect of CCA curriculum and how to teach it. The teacher should recognize fully his/her role as a facilitator of learning, a manager of the teaching-learning process and the need for maintaining the community-school link. This calls for certain competences, a sound knowledge of content and methodology and should be familiar with the nature of music.

The curriculum of CCA is arranged from year one to year three of the junior secondary school (JSS). The music aspect is organized around four major themes:

- Music in Society

- Effective Musical Practice

- Musical Literacy

- Effective Music Practice

These themes are sub-divided into topics in a way that music is presented in a logical manner from JSS one through three. For each year, the themes have topics along with performance objectives, the content, and activities for the teacher and the students, materials and evaluation guide. Some themes are recurring and are spiral in nature. The spiral nature of these themes ensures that the contents become gradually difficult as students progresses from year one to three. In the teaching of cultural and creative arts (music aspect), the teacher can always plan for collecting some materials that will enable him/her treat an idea, topic or skill that one has set out to transfer to the students. The teacher can go further to read textbooks on cultural and creative arts which treated the topic at hand. The following steps can help the teacher in achieving a meaningful collection of materials:

- Collect and read thoroughly some related reference materials such as the junior secondary school cultural and creative arts curriculum module, students' books on CCA and teacher's manual.

- Either make use of the suggested teaching materials, equipments and tools in the curriculum or improve materials that could serve the same purpose (improvisation).

- Ensure that you as the teacher can conveniently and effectively use these materials, equipment and tools before using them for class activities.

- Note the health and safety aspects of each material, equipment and tools collected before using them in class activity.

The instructional materials that can be used for effective teaching and learning of music may include the following: those suggested in the curriculum module, local musical instruments, available Western musical instruments, video tape recorder, pictorial reproduction, photographs, slides, film stripes, charts, flash cards, pictures, sound-producing objects, improvised sound-producing objects, musical scores, music manuscripts, solfa modulator, ICT facilities et cetera (FME, 2007). Others include: the teacher, the students, parents, community members. The teacher should continuously make 
contact with all such resources in music teaching.

Many methods/techniques of teaching abound, such as discussion, lecture, demonstration, project, field trip/excursion, discovery, process-based learning, questioning, active learning, scaffolding, brainstorming; computer assisted learning, co-operative learning et cetera. These methods are either conventional or non-conventional methods. Each of these methods/techniques can be made to be learner-centred if properly managed. CCA teacher needs to employ methods and techniques that will bring about permanent learning which is also learner centred, learner focused, learner-driven and learner friendly. CCA teacher is morally and professionally bound to carry out the teaching as an active performer. In the teacher's choice of instructional method the following should be taken into consideration:

- The music concept to be taught

- Available instructional materials

- Class size

- Duration of the lesson

- Prior knowledge

Adequate care must be taken in planning CCA lessons to ensure effective teaching and learning. Adequate lesson plan is a building block for effective teaching at the level of students. Teachers should have a firm grip of the fundamentals of the lesson plan and their import in purposeful teaching. Without adequate lesson plan, the teacher finds it difficult to maintain a focus and may end up teaching much but imparting little knowledge. Maduewesi (1999:18) asserted that it is 'the teacher's responsibility to create or influence desirable changes in behaviour or in tendencies towards behaviour in his students'.

For effective teaching of the content areas in the CCA curriculum, teachers need to be knowledgeable and skilful in construction of the teaching objectives using learner-friendly methods and techniques of teaching. The objective of a lesson determines how much a teacher wants to achieve in his/her lesson. It is a teacher's guide through out the period of the lesson. Teachers should aim at achieving performance based objective that is the result of a student's action which is observable and can be measured at the end of a lesson. 'A lesson without performance objective is like a missionary without a mission' (NTI, 2011:138). Performance objectives are stated using measurable verbs that is, verb that describes an action. Examples of measurable verbs for stating performance objectives include: to list, to describe, to state, to mention, to demonstrate, to interpret, to draw, to cut, to sketch, to apply, to carry out, to diagnose, to construct, to dismantle, to assemble, to distinguish, et cetera (NTI, 2011).

\section{Problems Militating Against Effective Teaching of CCA as an Integrated Subject}

The inability of the NERDC to consider that teachers have their area of subject specialization before integrating the CCA as a single subject to be taught by a single teacher is the major problem militating against effective teaching and learning of CCA in schools today. This has giving rise to so many other problems inherent in CCA. For a teacher to produce students with long lasting skills and critically aware state of mind that will enable them develop active learning, the teacher must have in-depth knowledge of the subject in order to create a classroom environment that can facilitate active learning. Music, drama and fine art no doubt, are essential elements of culture that give vibrancy and dept meaning to life in which their essence manifest through creative thinking and action. This creative aspect must have warranted their being integrated as one subject but it should be realised that each of these subjects has its own distinct characteristics and varied ways of working. Every teacher is groomed to have a speciality subject area and so, the teachers' area of specialization should be considered because none gives what he/she has not. It is inconceivable that teachers are subjected to teach what they know nothing about. The amount of creativity and practical the students are exposed to depend on the teachers' exposure. Lack of in-dept knowledge of the subject matter by the teacher may result to the following problems: Inability to meaningfully interpret the performance objectives; Skipping of unfamiliar content areas by the teacher; Inability to organize activities for students; Inability to identify sources of teaching aids; Lack of adequate communication skills; Lack of assessment skills; Inadequate and incompetent teachers; etc.

It is lamentable that several years after the integration of CCA into a single subject, many teachers of CCA still lack the awareness and knowledge of the concept of CCA. Most teachers do not show enough enthusiasm about the subject. Many teachers still grumble and make scathing remarks about the seriousness of the subject and its implementation thereby rendering the expectation of achieving effective learning and expected creativity questionable. Okonkwo (2009:54) lamented that 'there is the question of dedication and commitment of the teachers to updating their knowledge and searching for teaching materials'. The teachers cannot be totally blamed for their lack of enthusiasm because they were not exposed to in-service training and workshops that will enable them improve their pedagogical and 
communication skills. The National Teachers Institute, Kaduna (NTI) is one of the major institutions charged with the responsibility of training Nigerian teachers. They have done workshops and seminars for many disciplines both in primary and secondary schools but none has been done for teachers of CCA. Almost all the teachers complain that they were not given adequate orientation on the requirements of the subject in terms of workshops before the takeoff. Ekwueme (2011:42) confirmed the above and said, 'they never had any orientation on the implementation process for CCA'. Most CCA teachers especially, non music specialists find it very difficult to teach the music aspect. The situation now needs urgent intervention in order to address the decadence that is currently retarding the growth and achievement of the objective of NERDC. It is important to lay a solid foundation at this basic level instead of messing up the future of the children and the nation through a curriculum that have not been supported to succeed (http://tribune.com.ng).

\section{Suggestions}

This paper is advocating that NERDC should have a re-think about the integration of music, drama and fine art as a single subject for now. There is no need forcing the teachers to teach what they know nothing about. The teachers' area of subject specialization should be considered. This is because students at this level of education are active, creative and inquisitive and they learn practically through activities. The teachers who teach at this level should use more of participatory, exploratory and practically oriented methods to engage the students in teaching and learning by doing. The teachers can only achieve this if they have in-debt knowledge of their subject area. Reviewing of the curriculum usually takes time and since the system must move on till the curriculum is reviewed, this paper is equally suggesting the following:

The government should organise regular workshops and seminars for teachers of CCA to get them abreast with the subject matter contents. This will give the teachers more confidence in handling the contents of CCA and also boost their enthusiasm for their job. There is need to review the curriculum of CCA especially in the area of music in order to give a direction on integrated arts subjects. CCA as a subject is practical or skill oriented. There should be time allocated for practical.

Cultural and creative art is the totality of all arts in its aesthetic, communicative and visual forms. The teacher can keep some of the society's vanishing culture in focus through the classroom interaction with the students to impart knowledge of our existing culture. A competent teacher even if he/she is not a music specialist needs to do a lot of reading and visiting the internet for relevant materials for music teaching and learning. The teacher should take advantage of technological gadgets that are available to siphon information through the internet.

The teachers should be encouraged to put more effort in collecting instructional materials such as audio/visual aids, pictures, music instruments and other equipment. Students should also be encouraged to use multimedia tools, such as CD drive, to listen to music and watch educational films, projectors, computers, digital video disc (DVD), laser disc (LD),video compact disc (VCD) and player midi keyboard synthesis (Okonkwo, 2009).

The teacher should seek the assistance of more experienced teachers and obtain information about resources for teaching music. The teacher should study the new 9-year curriculum on creative arts and also study the text books on music regularly in order to be acquainted with the contents and how to handle them. This will serve as a guide to the teacher in teaching music concepts.

\section{Conclusion}

The thrust of this study has been to review the integration of CCA in Nigerian curriculum and suggest ways of enhancing the programme. It is also intended to make the curriculum planners realise the need for organising regular workshops and retraining exercises for the teachers of CCA especially now that the discipline is in dire need of dedicated, enthusiastic and innovative teachers who will not only develop the technique for teaching CCA as an integrated subject with lesser hazels but also bring the CCA to its desired place in the Nigerian curriculum.

However, it is the opinion of this writer that for the time being the CCA should be left and be taught as separate subjects until departments of CCA is created in the Nigerian colleges of education and other institutions where teachers are trained and produced for the basic classes. This will enable the teachers to be prepared right from their training schools to tackle the challenges ahead, possess the necessary skills to guide the students and encourage them to express their creativity through the Cultural and Creative Arts education. 


\section{References}

Arts integration-Wikipedia the free encyclopaedia. Available @ en.wikipedia.org/wiki/Arts_integration-cashed [Retrieved: 24 May, 2012].

Ekwueme, L. U. (1991). Cultural and creative arts education in Nigerian schools. A commissioned paper presented at the National Curriculum Review Conference. Conference Proceedings Federal Ministry of Education Policy and Implementation and Department.

Ekwueme, L. U. (2009). Competency-based teacher education in music/cultural and creative arts: A suggested approach for the universal basic education (UBE) programme. Interlink: A Journal of Research in music, 4, 33-47.

Federal Government of Nigeria (2007). The 9-year basic education curriculum at a glance. Abuja: NERDC.

Federal Ministry of Education (1988). National Curriculum on Cultural and Creative arts for Primary Schools. Lagos: Federal Ministry of Education.

Federal Ministry of Education (2007). 9-Year basic education curriculum cultural and creative arts for junior secondary 1-3. Abuja: Nigeria.

Federal Republic of Nigeria, (2004). National Policy on Education. Lagos: NERDC Press.

http://www.lagostelevision.com/.../minister-states-accessed-n50b-ubec-cash-in-2011-the-nation-newspaper/-31k [Retrieved:16 February, 2012].

http://www.reading.ac uk/a-z [Retrieved: 16 February, 2012].

http://www.ncceonline.org/.../Arts.../ [Retrieved: 24 May, 2012].

Maduewesi, B. U. (1999). The elements of education. In B. U. Maduewesi, L. U. Ezeani \& C. P. Maduewesi (Eds.), Curriculum implementation and instruction (pp. 15-30). Onitsha: West \& Solomon.

National Teachers' Institute (2011). Manual for the re-training of junior secondary school teachers in basic science and technology. Kaduna: NTI Press.

Nigerian Educational Research and Development Council (NERDC) (2007). The new 9-year basic education curriculum at a glance. Abuja: NERDC press.

Nwokenna, E. N. (2006). Competencies needed for effective teaching of music in the secondary schools. Awka Journal of Research in Music and the Arts (AJRMA), 3, 47-61.

Okafor, R. C. \& Okafor, C. U. (2009). Music and national development in Nigeria. Enugu: New Generation Books.

Okonkwo, V. N. (2009). Cultural and creative art as an educational tool for national development. Alvan Journal of Music and Humanities (AJOMAH), 1, (1), 50-58.

Towards a realistic lower basic education curriculum in Nigeria. Available at [http://tribune.com.ng] Retrieved: $2^{\text {nd }}$ November, 2012. 